\title{
Phylogeny of Fusarium oxysporum f. sp. lactucae Inferred from Mitochondrial Small Subunit, Elongation Factor 1- $\alpha$, and Nuclear Ribosomal Intergenic Spacer Sequence Data
}

\author{
Gladys Y. Mbofung, Soon Gyu Hong, and Barry M. Pryor
}

\begin{abstract}
First, second, and third authors: Division of Plant Pathology and Microbiology, Department of Plant Sciences, College of Agriculture and Life Sciences, University of Arizona, Tucson 85721; and second author: Polar Biocenter, Korea Polar Research Institute, KORDI, Songdo Technopark, Songdo-dong 7-50, Yeonsu-gu, Incheon, 406-840, Korea.
\end{abstract} Accepted for publication 7 August 2006.

\begin{abstract}
Mbofung, G. Y., Hong, S. G., and Pryor, B. M. 2007. Phylogeny of Fusarium oxysporum f. sp. lactucae inferred from mitochondrial small subunit, elongation factor $1-\alpha$, and nuclear ribosomal intergenic spacer sequence data. Phytopathology 97:87-98.

Fusarium oxysporum f. sp. lactucae, causal agent of Fusarium wilt of lettuce, is a serious pathogen recently reported in Arizona. Sequence analysis of the mitochondrial small subunit ( $\mathrm{mtSSU})$, translation elongation factor $1-\alpha(E F-1 \alpha)$ gene, and the nuclear ribosomal DNA intergenic spacer (IGS) region was conducted to resolve relationships among f. sp. lactucae isolates, F. oxysporum isolates from other hosts, and local nonpathogenic isolates. Analysis of mtSSU sequences provided limited

phylogenetic resolution and did not differentiate the lactucae isolates from 13 other $F$. oxysporum isolates. Analysis of EF-1 $\alpha$ sequences resulted in moderate resolution, grouping seven formae speciales with the lactucae isolates. Analysis of the IGS region revealed numerous sequence polymorphisms among $F$. oxysporum formae speciales consisting of insertions, deletions, and single nucleotide transitions and substitutions. Repeat sequence analysis revealed several duplicated subrepeat units that were distributed across much of the region. Based on analysis of the IGS sequence data, lactucae race 1 isolates resolved as a monophyletic group with three other formae speciales of $F$. oxysporum. In all analyses, lactucae race 2 isolates composed a separate lineage that was phylogenetically distinct and distantly related to the lactucae race 1 isolates.
\end{abstract}

Fusarium wilt of lettuce was first reported in 1967 when it was responsible for significant losses in lettuce in Japan. The causal organism was determined to be Fusarium oxysporum f. sp. lactucae Schlechtend.:Fr. Matuo and Motohashi (22) and pathogenicity on lettuce was confirmed. In the United States, the disease was first reported in the San Joaquin valley of California in 1993, where it was responsible for lettuce losses in three fields near the town of Huron (18). The disease subsequently was reported in Arizona in 2001 in 5 fields near the town of Yuma and in 11 additional fields during the 2002-03 cropping season (21). The occurrence of the disease in both Arizona and California is particularly serious due to its damaging nature and the importance of lettuce production to both agricultural economies. Worldwide, the disease has been reported in three other countries: Taiwan (1996), Iran (1999), and Italy (2001) (12,17,25).

Strains of $F$. oxysporum exhibit considerable physiological variation. The fungus is found worldwide and commonly is isolated from nearly all soil types. Both pathogenic and nonpathogenic forms are able to colonize many plants and crop residues, as well as being capable of rapidly recolonizing fumigated soils (14). Pathogenic forms often display a high degree of host specificity, and numerous formae speciales have been described. Within each forma specialis, races have been identified based on the differential host cultivars on which the races cause disease (4). Regarding the f. sp. lactucae, three races have been identified to date with races 1,2 , and, most recently, 3 present in Japan (10). Only race 1 has been reported in the United States $(10,23)$.

Corresponding author: Barry M. Pryor; Email address: bmpryor@ag.arizona.edu

DOI: 10.1094/PHYTO-97-0087

(c) 2007 The American Phytopathological Society
Distinguishing formae speciales in the F. oxysporum spp. complex most often requires pathogenicity tests. Although isolates within a forma specialis are related by their pathogenicity to a given host, genetic heterogeneity within certain formae speciales often has revealed a polyphyletic origin (14). This heterogeneity has important implications on the evolution of pathogenic forms within the species, and on the development of resistant host cultivars. Therefore, it is critical to be able to quickly and accurately differentiate genetic diversity. Many molecular methods have been used to differentiate between nonpathogenic and pathogenic forms of $F$. oxysporum. Mitochondrial haplotype analysis and sequence analysis of the mitochondrial small subunit (mtSSU), translation elongation factor $1-\alpha(\mathrm{EF}-1 \alpha)$ gene, and nuclear ribosomal (r)DNA intergenic spacer (IGS) region have been used to determine diversity within certain formae speciales such as melonis, cucumerinum, vasinfectum, cubense, and lycopersici $(3,27,33)$. The IGS region contains greater sequence variation than the other genomic regions and, thus, may have greater utility in phylogenetic analyses. However, analyses to date have been limited to restriction fragment length polymorphisms or partial sequences, or have focused on human pathogens $(2,3,11,28)$.

The objective of the present study was to determine phylogenetic relationships among $F$. oxysporum $\mathrm{f}$. sp. lactucae isolates, native nonpathogenic $F$. oxysporum isolates from Arizona, and selected formae speciales based on mtSSU, EF- $1 \alpha$, and full-length IGS sequences. These data will be valuable in understanding the origin and genetic diversity of the pathogen in Arizona, and in the identification of pathogen-specific molecular markers that may be used in the development of DNA-based methods of detection.

\section{MATERIALS AND METHODS}

Fungal isolates. Sources of the isolates used in this study are listed in Table 1. F. oxysporum isolates from Arizona were re- 
covered from infected lettuce tissue and from field soil using standard phytopathological isolation techniques and standard soil dilution techniques, respectively. For recovery from lettuce, tissue was surfaced sterilized in $10 \% \mathrm{NaOCl}$ and $5-\mathrm{mm}^{3}$ pieces were cut from the advancing margins of the disease symptom and plated on Komada's medium (19). Putative F. oxysporum colonies were subcultured on identification media (Komada's, potato dextrose agar [PDA, Difco brand; Becton, Dickinson and Co., Franklin Lakes, NJ], and $0.5 \% \mathrm{KCl}$ medium) (6) and their identity was confirmed by morphological characterization. For recovery from soil, $10 \mathrm{~g}$ of each soil sample ( $\approx 200$ to $300 \mathrm{~g}$ total for each field soil sample) were suspended in $200 \mathrm{ml}$ of $1 \%$ sodium hexametaphosphate and stirred for $8 \mathrm{~min}$. The suspension $(20 \mathrm{ml})$ was added to $80 \mathrm{ml}$ of $0.1 \%$ water agar and stirred for $5 \mathrm{~min}$. Five plates of Komada's selective medium each were inoculated with $1 \mathrm{ml}$ of the suspension per soil sample. Following 7 days of incu- bation at $25^{\circ} \mathrm{C}$, putative $F$. oxysporum colonies then were isolated in pure cultures and identification was performed as described previously.

Also included were f. sp. lactucae race 1 isolates from California (HL1 [ATTC 76616] and HL2) and race 1 and race 2 isolates from Japan (S-1, and FK09701 and FK9501, respectively). Additional formae speciales of $F$. oxysporum were selected based on their pathogenicity on host species belonging to the same plant family as lettuce (Asteraceae) as well as those from phylogenetically diverse plant families.

Pathogenicity tests. Putative $F$. oxysporum f. sp. lactucae isolated from diseased lettuce tissue and field soil, and isolates obtained from collaborators in California and Japan, were tested for pathogenicity on three major commercial lettuce cultivars (Beacon, Lighthouse, and Winterhaven). The roots of 10-day-old seedlings were washed in running tap water and $\approx 1 \mathrm{~cm}$ of root tip

TABLE 1. Isolates used in this study and associated sequences with GenBank accession number noted ${ }^{\vee}$

\begin{tabular}{|c|c|c|c|c|c|}
\hline \multirow[b]{2}{*}{ Strain $^{\mathrm{w}}$} & \multirow[b]{2}{*}{ Species name ${ }^{\mathrm{X}}$} & \multirow[b]{2}{*}{ Geographic origin ${ }^{y}$} & \multicolumn{3}{|c|}{ GenBank accession $^{z}$} \\
\hline & & & mtSSU & $\mathrm{EF}-1 \alpha$ & IGS \\
\hline BMP1300 & Fusarium oxysporum f. sp. lactucae & Wellton, AZ & DQ831907 & DQ837658 & DQ831864 \\
\hline BMP1301 & F. oxysporum f. sp. lactucae $e^{\mathrm{p}}$ & Wellton, AZ & DQ831908 & DQ837659 & DQ831865 \\
\hline BMP1306 & F. oxysporum f. sp. lactucae $e^{\mathrm{p}}$ & Wellton, AZ & DQ831909 & DQ837660 & DQ831866 \\
\hline BMP1307 & F. oxysporum f. sp. lactucae $e^{\mathrm{p}}$ & Wellton, AZ & DQ831910 & DQ837661 & DQ831867 \\
\hline BMP1308 & F. oxysporum f. sp. lactucae $\mathrm{e}^{\mathrm{p}}$ & Wellton, AZ & DQ831911 & DQ837662 & DQ831868 \\
\hline BMP1323 & F. oxysporum f. sp. lactucae $\mathrm{e}^{\mathrm{p}}$ & Wellton, AZ & DQ831912 & DQ837663 & DQ831869 \\
\hline BMP1324 & F. oxysporum f. sp. lactucae $e^{\mathrm{p}}$ & Wellton, AZ & DQ831913 & DQ837664 & DQ831870 \\
\hline BMP1326 & F. oxysporum f. sp. lactucae $e^{\mathrm{p}}$ & Wellton, AZ & DQ831914 & DQ837665 & DQ831871 \\
\hline BMP1331 & F. oxysporum f. sp. lactucae $e^{\mathrm{p}}$ & Wellton, AZ & DQ831915 & DQ837666 & DQ831872 \\
\hline BMP1333 & F. oxysporum f. sp. lactucae $e^{\mathrm{p}}$ & Wellton, AZ & DQ831916 & DQ837667 & DQ831873 \\
\hline HL-1 & F. oxysporum f. sp. lactucae $e^{\mathrm{p}}$ & Fresno, CA & DQ831918 & DQ837668 & DQ831874 \\
\hline HL-2 & F. oxysporum f. sp. lactucae ${ }^{\mathrm{p}}$ & Fresno, CA & DQ831919 & DQ837669 & DQ831875 \\
\hline BMP1880 & F. oxysporum f. sp. lactucae (soil) $^{\mathrm{p}}$ & Wellton, AZ & DQ831917 & DQ837670 & DQ831879 \\
\hline BMP1363 & F. oxysporum f. sp. lactucae (soil) $^{\mathrm{p}}$ & Wellton, AZ & DQ831921 & DQ837671 & DQ831876 \\
\hline BMP1370 & F. oxysporum f. sp. lactucae ${ }^{\mathrm{p}}$ (soil) & Wellton, AZ & DQ831922 & DQ837672 & DQ831877 \\
\hline BMP1375 & F. oxysporum f. sp. lactucae (soil) $^{\mathrm{p}}$ & Wellton, AZ & DQ831920 & DQ837673 & DQ831878 \\
\hline BMP1389 & F. oxysporum ${ }^{\mathrm{np}}$ (soil) & Yuma, AZ & DQ831926 & DQ837676 & DQ831881 \\
\hline BMP1397 & F. oxysporum ${ }^{\mathrm{np}}$ (soil) & Yuma, AZ & DQ831924 & DQ837677 & DQ831882 \\
\hline BMP1388 & F. oxysporum ${ }^{\mathrm{np}}$ (soil) & Yuma, AZ & DQ831925 & DQ837675 & DQ831883 \\
\hline BMP1385 & F. oxysporum ${ }^{\mathrm{np}}$ (soil) & Wellton, AZ & DQ831923 & DQ837674 & DQ831880 \\
\hline S-1 & F. oxysporum f. sp. lactucae $e^{\mathrm{p}}$ & Japan & DQ831906 & DQ837657 & DQ831863 \\
\hline F9501 & F. oxysporum f. sp. lactucae $e^{\mathrm{p}}$ & Japan & DQ831944 & DQ837693 & DQ831893 \\
\hline FK09701 & F. oxysporum f. sp. lactucae $\mathrm{p}^{\mathrm{p}}$ & Japan & DQ831945 & DQ837694 & DQ831892 \\
\hline FOV14 & F. oxysporum f. sp. vasinfectum ${ }^{\text {nd }}$ & California & DQ831942 & DQ837695 & DQ831885 \\
\hline TX388 & F. oxysporum f. sp. melonis ${ }^{\text {nd }}$ & Texas & DQ831943 & DQ837696 & DQ831887 \\
\hline FOLR2 & F. oxysporum f. sp. lycopersici $i^{\text {nd }}$ & California & DQ831941 & DQ837692 & DQ831894 \\
\hline FOA50 & F. oxysporum f. sp. asparagi $i^{\text {nd }}$ & Australia & DQ831940 & DQ837691 & DQ831886 \\
\hline NRRL22536 & F. oxysporum f. sp. callistephi $i^{\text {nd }}$ & Germany & DQ831928 & DQ837679 & DQ831897 \\
\hline NRRL22535 & F. oxysporum f. sp. batatas $^{\text {nd }}$ & Germany & DQ831927 & DQ837678 & DQ831895 \\
\hline NRRL26871 & F. oxysporum f. sp. spinaciae sd $^{\text {nd }}$ & Japan & DQ831938 & DQ837687 & DQ831888 \\
\hline NRRL26445 & F. oxysporum f. sp. phaseoli ${ }^{\text {nd }}$ & South Carolina & DQ831934 & DQ837686 & DQ831900 \\
\hline NRRL28934 & F. oxysporum f. sp. opuntiarum ${ }^{\text {nd }}$ & Netherlands & DQ831939 & DQ837689 & DQ831884 \\
\hline NRRL22546 & F. oxysporum f. sp. medicaginis ${ }^{\text {nd }}$ & SE Asia & DQ831937 & DQ837690 & DQ831901 \\
\hline NRRL22538 & F. oxysporum f. sp. cepae $e^{\text {nd }}$ & Germany & DQ831929 & DQ837681 & DQ831891 \\
\hline NRRL25231 & F. oxysporum f. sp. vasinfectum ${ }^{\text {nd }}$ & North Carolina & DQ831931 & DQ837680 & DQ831896 \\
\hline NRRL26412 & F. oxysporum f. sp. heliotropa $a^{\text {nd }}$ & Maryland & DQ831933 & DQ837685 & DQ831903 \\
\hline NRRL26411 & F. oxysporum f. sp. fabae $e^{\text {nd }}$ & Maryland & DQ831936 & DQ837684 & DQ831902 \\
\hline NRRL26227 & F. oxysporum f. sp. rhois ${ }^{\mathrm{np}}$ & Israel & DQ831932 & DQ837683 & DQ831898 \\
\hline NRRL22545 & F. oxysporum f. sp. matthiolae ${ }^{\text {nd }}$ & Germany & DQ831930 & DQ837682 & DQ831899 \\
\hline NRRL22550 & F. oxysporum f. sp. perniciosum ${ }^{\text {nd }}$ & N/A & AF008472 & AF008506 & ARS \\
\hline NRRL26035 & F. oxysporum f. sp. canariensis ${ }^{\text {nd }}$ & N/A & AF008451 & AF008485 & ARS \\
\hline NRRL26029 & F. oxysporum f. sp. cubense $e^{\text {nd }}$ & N/A & AF008459 & AF008493 & ARS \\
\hline NRRL28378 & F. commune $^{\text {nd }}$ & Netherlands & AF250560 & AF246832 & ARS \\
\hline BMP1462 & F. subglutinans $s^{\text {nd }}$ & Wellton, AZ & DQ831946 & DQ837698 & DQ831904 \\
\hline
\end{tabular}

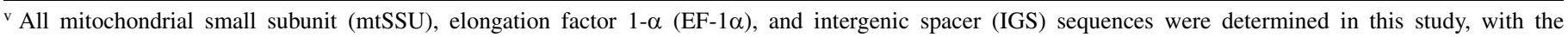
exception of those with accession numbers in bold.

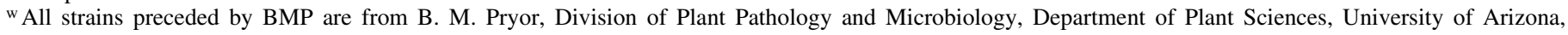
Tucson; all strains preceded by NRRL are from K. O’Donnell (ARS culture collection), National Center for Agricultural Utilization Research, Peoria; FOA50 is from E. Nigh, division of Plant Pathology and Microbiology, Department of Plant Sciences, University of Arizona, Tucson; and all other strains are from T. Gordon, Department of Plant Pathology, University of California, Davis.

${ }^{x}$ Superscripts: $\mathrm{p}=$ pathogenic on lettuce, $\mathrm{np}=$ not pathogenic on lettuce, and nd = pathogenicity on lettuce not determined.

y N/A = geographic origin of the strain is not available. The lactucae isolates recovered from soil are noted (soil).

${ }^{\mathrm{z}} \mathrm{ARS}=\mathrm{IGS}$ sequences of these isolates were obtained through courtesy of Kerry O'Donnell. 
was removed. The wounded roots were dipped in a spore suspension containing $1 \times 10^{6}$ spores $/ \mathrm{ml}$ for $10 \mathrm{~min}$. For each fungal isolate-lettuce cultivar combination, eight inoculated seedlings were transplanted to $20-\mathrm{cm}$-wide plastic pots containing a sterile mix of one part peat, one part vermiculite, and two parts sand $(1: 1: 2)$. The experiment was set up in the greenhouse $\left(24\right.$ to $29^{\circ} \mathrm{C}$, relative humidity $=50$ to $60 \%$ ) in a completely randomized design. Each plant was rated for disease 20 days after inoculation using a scale of 0 to 3 , where $0=$ no disease symptoms, $1=$ plant stunted compared with control, 2 = plant severely stunted, and $3=$ plant dead. Disease incidence was calculated for each isolate-cultivar combination. In addition, a disease index was calculated for each isolate-cultivar combination using the formula $\left(\mathrm{n}_{1}\right)+\left(\mathrm{n}_{2} \times 2\right)+\left(\mathrm{n}_{3} \times\right.$
3)/ $\left(\mathrm{n}_{0}+\mathrm{n}_{1}+\mathrm{n}_{2}+\mathrm{n}_{3}\right)$, where $\mathrm{n}_{0}$ is the number of plants in the disease category $0, \mathrm{n}_{1}$ is the number of plants in the disease category $1, \mathrm{n}_{2}=$ number of plants in the disease category 2 , and $\mathrm{n}_{3}$ represents the number of plants in the disease category 3 (10). Disease index data was analyzed by one-way analysis of variance (SigmaStat, ver. 3.1; Jandel Scientific, San Rafael, CA) to determine differences in virulence among isolates on each cultivar. The experiment was repeated once.

DNA isolation and sequence amplification. Five-day-old cultures of the test fungi grown on PDA were flooded with $5 \mathrm{ml}$ of sterile water and the surface of the culture was scrapped with a spatula to obtain spores and mycelia in suspension. The spore or mycelia suspension $(2 \mathrm{ml})$ was used to inoculate $100 \mathrm{ml}$ of liquid

TABLE 2. Primers pairs for genomic regions amplified and sequenced in this study

\begin{tabular}{|c|c|c|}
\hline Locus $^{\mathrm{z}}$ & Primer sequence & Reference \\
\hline \multicolumn{3}{|c|}{ Mitochondrial small subunit } \\
\hline $\mathrm{NMS1}^{\mathrm{a}}$ & 5'-CAGCAGTGAGGAATATTGGTCAATG-3' & Li et al. 1994 (20) \\
\hline $\mathrm{NMS} 2^{\mathrm{b}}$ & 5'-GCGGATCATCGAATTAAATAACAT-3' & Li et al. 1994 (20) \\
\hline $\mathrm{EF}-1 \mathrm{H}^{\mathrm{a}}$ & 5'-ATGGGTAAGGAAGACAAGAC-3' & O’Donnell et al. 1998 (27) \\
\hline $\mathrm{EF}-2 \mathrm{~T}^{\mathrm{b}}$ & 5'-GGAAGTACCAGTGATCATGTT-3' & O’Donnell et al. 1998 (27) \\
\hline \multicolumn{3}{|c|}{ Intergenic spacer region } \\
\hline $\mathrm{CNL} 12^{\mathrm{a}}$ & 5'-CTGAACGCCTCTAAGTCAG-3' & Anderson and Stasovski 1992 (1) \\
\hline RU46.67 & 5'-GTGTCGGCGTGCTTGTATT-3' & This study \\
\hline $\mathrm{CN}_{61}^{\mathrm{a}}$ & 5'-GGTTCAATTTGATGTCGGCT-3' & This study \\
\hline $\mathrm{RCN}_{6} 1^{\mathrm{b}}$ & 5'-AGCCGACATCAAATTGACC-3' & This study \\
\hline RU3 $^{\mathrm{a}}$ & 5'-GTGTGAAATTGGAAAGTCGG-3' & This study \\
\hline RRU3 $^{\mathrm{b}}$ & 5'-CCGACTTTCCAATTTCACAC-3' & This study \\
\hline $\mathrm{CN} 34^{\mathrm{b}}$ & 5'-CCAACACATGGGTGGTACCG-3' & This study \\
\hline IGSF4 $^{\mathrm{a}}$ & 5'-CCAGACTTCCACTGCGTGTC-3' & This study \\
\hline
\end{tabular}

${ }^{\mathrm{z}}$ Superscripts: $\mathrm{a}=$ forward primers and $\mathrm{b}=$ reverse primers.

A

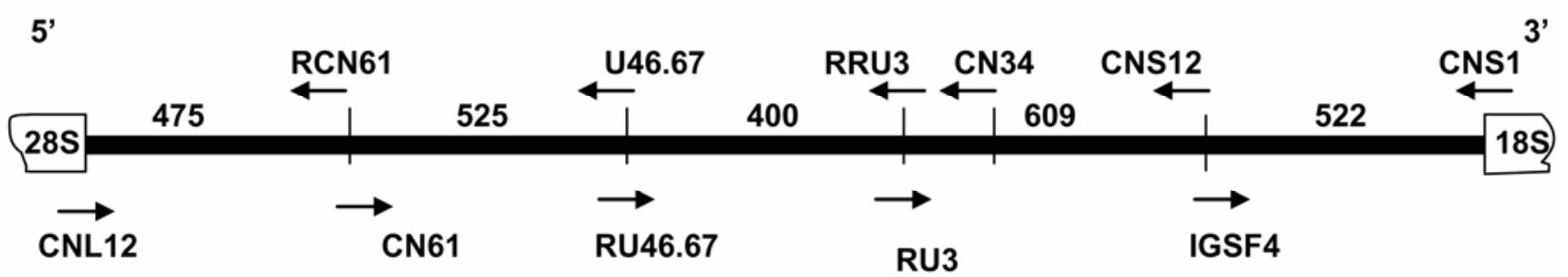

B

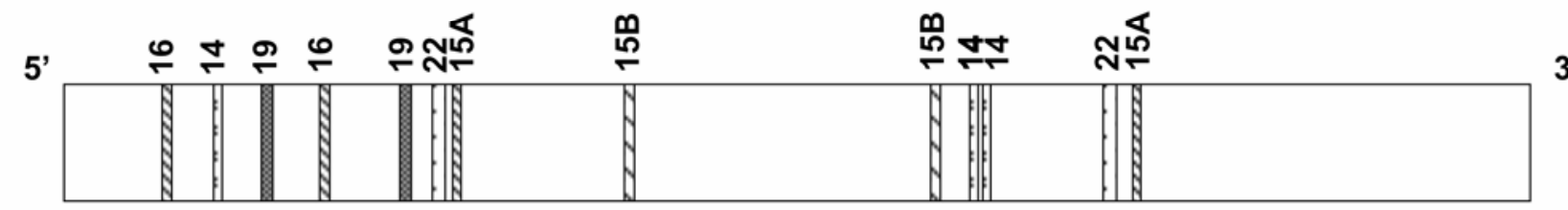

$\overline{150 \mathrm{bp}}$

Fig. 1. A, Diagrammatic representation of the ribosomal DNA intergenic spacer (IGS) region within one tandem repeat. Except for primers CNL12, CNS1, and U47.67, all other primers were designed in this study. The numbers on the figure is the estimated size in base pairs of the amplification product that could be obtained using each flanking primer set. B, Pattern of distribution of repeat sequences within the IGS of Fusarium oxysporum f. sp. lactucae using the program DNA strider allowing for no mismatch of base pairs and no overlap of repeat sequence. 
growth medium (1.2 $\mathrm{g}$ of DL-asparagine, $0.2 \mathrm{~g}$ of $\mathrm{NaCl}, 1.2 \mathrm{~g}$ of $\mathrm{K}_{2} \mathrm{HPO}_{4} \cdot 3 \mathrm{H}_{2} \mathrm{O}, 0.25 \mathrm{~g}$ of $\mathrm{MgSO}_{4}, 0.5 \mathrm{~g}$ of yeast extract, and $20.7 \mathrm{~g}$ of D-glucose in 1 liter of water) and was incubated at room temperature for 5 days on a rotary shaker $(120 \mathrm{rpm})$. The mycelia were harvested by filtration through miracloth (Calbiochem; EMD Biosciences Inc., San Diego, CA), frozen, and lyophilized. Total DNA was prepared from a sample of $50 \mathrm{mg}$ of lyophilized mycelia using the BIO 101 Fast DNA kit (Qbiogene, Irvine, CA) according to the manufacturer's instructions. Polymerase chain reaction (PCR) was performed to amplify the mtSSU, EF- $1 \alpha$ gene, and IGS rDNA using specific primers (Table 2). Each PCR reaction contained $0.2 \mathrm{mM}$ deoxynucleotide triphosphates, $2.5 \mathrm{mM}$ Amplitaq $\mathrm{MgCl}_{2}, 0.8 \mu \mathrm{M}$ each primer, 1× Amplitaq reaction buffer, and 2 units of Amplitaq DNA polymerase (Applied Biosciences, Foster City, CA). PCR reactions were carried out in a PTC-100 thermal cycler (MJ Research, Inc., Watertown, MA) using the following steps for 35 cycles: $94^{\circ} \mathrm{C}$ for $1 \mathrm{~min}, 60^{\circ} \mathrm{C}$ for $1.5 \mathrm{~min}$, and $72^{\circ} \mathrm{C}$ for $2 \mathrm{~min}$. For primers U46.67, RU46.67, and RRU3, the PCR annealing temperature was set at $63^{\circ} \mathrm{C}$. The amplified products were purified with the aid of a QIAquick PCR purification kit (Qiagen Inc., Stanford, CA). The cleaned PCR products were sequenced at the DNA Sequencing Facility, University of Arizona. Due to its large size $(\approx 2,600 \mathrm{bp})$, the complete sequence of the IGS region required the design of additional internal primers, and sequencing was performed in both directions to confirm the nucleotide sequence (Table 2). The map of the amplification and sequencing primers for the IGS region are presented in Figure 1A. All IGS as well as the mtSSU and EF-1 $\alpha$ sequences have been submitted to GenBank (Table 1) and their alignments have been submitted to TreeBASE (SN2653-10318).

TABLE 3. Disease incidence and disease index of Fusarium oxysporum isolates on three iceberg lettuce cultivars (Beacon, Lighthouse, and Winterhaven) commonly used in Arizona

\begin{tabular}{|c|c|c|c|c|}
\hline \multirow[b]{2}{*}{ Isolate } & \multicolumn{3}{|c|}{ Disease incidence $(\%)$, disease index ${ }^{y}$} & \multirow[b]{2}{*}{ Path. ${ }^{\mathrm{z}}$} \\
\hline & Beacon & Lighthouse & Winterhaven & \\
\hline HL2 & $100,2.6 \mathrm{ab}$ & $100,3.0 \mathrm{a}$ & $100,2.8 \mathrm{a}$ & $\mathrm{P}$ \\
\hline HL1 & $100,2.6 \mathrm{ab}$ & $100,2.6 \mathrm{ab}$ & $100,2.6 \mathrm{a}$ & $\mathrm{P}$ \\
\hline $\mathrm{JCP} 007$ & $100,3.0 \mathrm{a}$ & $100,2.6 \mathrm{ab}$ & $100,2.6 \mathrm{a}$ & $\mathrm{P}$ \\
\hline BMP1323 & $100,2.8 \mathrm{ab}$ & $100,2.9 \mathrm{a}$ & $100,2.6 \mathrm{a}$ & $\mathrm{P}$ \\
\hline BMP1324 & $100,3.0 \mathrm{a}$ & $87.5,1.8 \mathrm{~b}$ & $100,2.5 \mathrm{a}$ & $\mathrm{P}$ \\
\hline BMP1326 & $100,3.0 \mathrm{a}$ & $100,2.5 \mathrm{ab}$ & $100,2.6 \mathrm{a}$ & $\mathrm{P}$ \\
\hline BMP1331 & $100,2.9 \mathrm{a}$ & $100,2.8 \mathrm{a}$ & $100,2.9 \mathrm{a}$ & $\mathrm{P}$ \\
\hline BMP1300 & $100,2.2 \mathrm{~b}$ & $100,2.2 \mathrm{ab}$ & $100,2.6 \mathrm{a}$ & $\mathrm{P}$ \\
\hline BMP1301 & $100,2.6 \mathrm{ab}$ & $100,2.6 \mathrm{ab}$ & $100,2.6 \mathrm{a}$ & $\mathrm{P}$ \\
\hline BMP1306 & $100,2.5 \mathrm{ab}$ & $100,2.9 \mathrm{a}$ & $100,2.8 \mathrm{a}$ & $\mathrm{P}$ \\
\hline BMP1308 & $100,2.5 \mathrm{ab}$ & $100,2.6 \mathrm{ab}$ & $100,3.0 \mathrm{a}$ & $\mathrm{P}$ \\
\hline BMP1307 & $100,3.0 \mathrm{a}$ & $100,3.0 \mathrm{a}$ & $100,2.5 \mathrm{a}$ & $\mathrm{P}$ \\
\hline BMP1333 & $100,3.0 \mathrm{a}$ & $100,2.1 \mathrm{ab}$ & $100,3.0 \mathrm{a}$ & $\mathrm{P}$ \\
\hline BMP1880 & $100,3.0 \mathrm{a}$ & $100,3.0 \mathrm{a}$ & $100,3.0 \mathrm{a}$ & $\mathrm{P}$ \\
\hline BMP1375 & $100,3.0 \mathrm{a}$ & $100,3.0 \mathrm{a}$ & $100,3.0 \mathrm{a}$ & $\mathrm{P}$ \\
\hline BMP1363 & $100,2.8 \mathrm{ab}$ & $100,3.0 \mathrm{a}$ & $100,3.0 \mathrm{a}$ & $\mathrm{P}$ \\
\hline BMP1370 & $100,2.9 \mathrm{a}$ & $100,3.0 \mathrm{a}$ & $100,3.0 \mathrm{a}$ & $\mathrm{P}$ \\
\hline F9501 & $100,3.0 \mathrm{a}$ & $100,2.9 \mathrm{a}$ & $100,3.0 \mathrm{a}$ & $\mathrm{P}$ \\
\hline FK9701 & $100,2.9 \mathrm{a}$ & $100,2.9 \mathrm{a}$ & $100,3.0 \mathrm{a}$ & $\mathrm{P}$ \\
\hline S-1 & $100,3.0 \mathrm{a}$ & $100,2.9 \mathrm{a}$ & $100,2.6 \mathrm{a}$ & $\mathrm{P}$ \\
\hline BMP1389 & 0,0 & 0,0 & 0,0 & NP \\
\hline BMP1397 & 0,0 & 0,0 & 0,0 & NP \\
\hline BMP1388 & 0,0 & 0,0 & 0,0 & NP \\
\hline BMP1385 & 0,0 & 0,0 & 0,0 & NP \\
\hline NRRL26227 & 0,0 & 0,0 & 0,0 & NP \\
\hline $0.5 \% \mathrm{KCl}$ & 0,0 & 0,0 & 0,0 & NP \\
\hline
\end{tabular}

y Each treatment consisted of eight inoculated plants per cultivar. The disease incidence/severity was assessed with a 0 -to- 3 scale where $0=$ no disease, $1=$ plants stunted, $2=$ plants severely stunted, and $3=$ plants dead. The disease index was calculated using the formula $\left(\mathrm{n}_{1}\right)+\left(\mathrm{n}_{2} \times 2\right)+\left(\mathrm{n}_{3} \times 3\right) /\left(\mathrm{n}_{0}+\mathrm{n}_{1}+\right.$ $\left.\mathrm{n}_{2}+\mathrm{n}_{3}\right)$, where $\mathrm{n}_{0}, \mathrm{n}_{1}, \mathrm{n}_{2}$, and $\mathrm{n}_{3}$ represent the number of plants with scores of $0,1,2$, and 3 , respectively. Disease index values followed by a different letter were significantly different $(P \leq 0.05)$ based upon Tukey's test.

${ }^{\mathrm{z}}$ Path. = determination of pathogenicity: $\mathrm{P}=$ pathogenic and $\mathrm{NP}=$ nonpathogenic.
Phylogenetic analysis. The sequences were aligned using the PILEUP program of the GCG Sequence Analysis Software Package (ver. 10.2; Accelrys, Inc., San Diego, CA). Manual adjustments of sequence alignments were performed with the aid of the data editor program of MacClade phylogenetic software (ver. 4.0; Sinauer Associates, Inc., Sunderland, MA). Phylogenetic analyses were performed using the Phylogenetic Analysis Using Parsimony package (PAUP, ver. 4.0b10; Sinauer Associates). Heuristic searches for the most-parsimonious trees were conducted with random stepwise addition (1,000 replications) and branch swapping algorithm using tree bisection-reconnection (TBR). For the parsimony criterion, analysis of data sets were performed with gaps set as either missing data or as a fifth state. For each analysis, clade stability was assessed using 1,000 bootstrap replications. For maximum likelihood analysis, heuristic searches were conducted using best fit models selected by Akaike Information Criterion using Modeltest (ver. 3.07). Clade stability was assessed using 500 bootstrap replicates with rearrangements limited to 10,000 per replicate to reduce computational time. Two Fusarium spp., $F$. subglutinans and $F$. commune, were used as outgroups in all analyses. Analysis of repetitive sequence subunits found in the IGS was performed using the program DNA Strider (ver. 1.3f16; Institute for Marine Biosciences, National Research Council, Halifax, NS, Canada).

Combined data analysis. The data sets were concatenated and partitioned by genetic locus. The Mickevich-Farris incongruence metric $\left(I_{\mathrm{MF}}\right)$ was used to measure the total amount of incongruence between data partitions (24). The partition-homogeneity test (P-H, PAUP ver. 4.0b10; Sinauer Associates) was used to obtain $P$ values corresponding to each $I_{\mathrm{MF}}$ index to determine data partition combinability. The data partitions were analyzed pairwise and in total using maximum parsimony and maximum-likelihood criterion as described above.

Test of hypothesis. The parsimony criterion (9) also was used to test congruency of data sets against hypotheses for groupings drawn from results from mtSSU, EF-1 $\alpha$, and IGS sequence data. For each data set, a strict consensus tree was generated and used as a topological hypothesis. Heuristic searches were performed on alternative data sets under the constraint of each hypothesis using TBR branch swapping and random sequence addition (1,000 reps) algorithms applied in PAUP. All equally most parsimonious trees generated from each tree reconstruction condition were compared with the best trees generated without any constraint by KishinoHasegawa (KH), Templeton, and Winning-sites (WS) tests implemented in PAUP. The KH test $(13,15)$ estimates the standard error and confidence intervals for the difference in log-likelihoods between two topologically distinct phylogenetic trees representing hypotheses that might explain particular aligned sequence data sets. The Templeton test under the maximum parsimony criterion evaluates the topological congruence between trees produced from unconstrained searches and trees obtained in constrained monophyly of particular groupings (16). The WS test uses a signrank test with a one-tail binomial probability to determine significant differences among pairwise comparisons of alternative hypotheses (32). Thus, the results of the three tests should give similar interpretation of the data under study.

\section{RESULTS}

Pathogenicity tests. All $F$. oxysporum isolates recovered from diseased lettuce roots $(n=43)$ and those supplied by collaborators (race 1 and race 2) were pathogenic on all of the three lettuce cultivars used and were confirmed to be $F$. oxysporum f. sp. lactucae (Table 1). Among the $F$. oxysporum isolates recovered from soil in Arizona $(n=38), \approx 65 \%$ were pathogenic on all three lettuce cultivars used and were confirmed to be $F$. oxysporum f. sp. lactucae. For each isolate-cultivar combination, disease incidence was generally 0 or $100 \%$ (Table 3 ). Thus, the determination of pathogeni- 
city was unambiguous and the utility of the three cultivars for confirmation of pathogenicity for f. sp. lactucae race 1 and race 2 isolates was evident. The disease index values for each isolates confirmed as f. sp. lactucae ranged from 1.8 to 3.0, depending on pairing of isolate and lettuce cultivar (Table 3). There was no significant difference $(P=0.071)$ in disease index among isolates on cv. Winterhaven (Table 3). However, there were significant differences $(P<0.001)$ in disease index among isolates on cvs. Beacon and Lighthouse (Table 3). When the experiment was repeated, results were very similar, with the exception of BMP1324 on cv. Lighthouse, in which case the disease incidence increased to $100 \%$ and the disease index increased to 2.2 . Of the $F$. oxysporum isolates recovered from soil, four of the pathogenic and four of the nonpathogenic isolates were selected for inclusion in subsequent phylogenetic analyses (Table 1).

DNA amplification. The mtSSU primers NMS1 and NMS2 amplified fragments ranging in size between 730 and $739 \mathrm{bp}$ from all isolates. The EF-1 $\alpha$ primers EF-1H and EF-2T amplified fragments between of 709 and 721 bp from all isolates. The IGS primers CNL12 and CNS1 generated a product between 2,547 and 2,600 bp from all isolates. Internal primers used to generate smaller fragments of the IGS for sequencing generated products that ranged between 400 and $609 \mathrm{bp}$.

mtSSU phylogeny. Alignment of the mtSSU sequences resulted in a data set of 683 characters, of which 15 (2.2\%) were parsimony informative. Parsimony analysis resulted in one mostparsimonious tree (MPT) with three distinct clades (steps $=49$, consistency index $[\mathrm{CI}]=0.918$, retention index $[\mathrm{RI}]=0.946$ ) (Fig. 2). The major clade 3 included all lactucae race 1 isolates, 13 other non-lactucae isolates, and nonpathogenic isolates with strong bootstrap support (96\%). Clade 2, grouping together formae speciales (f. spp.) spinaciae, vasinfectum 2 (FOV14), and melonis, had a bootstrap support of $58 \%$. The f. sp. medicaginis did not cluster with either of the previous two clades. The two race 2 isolates (F9501 and FK09701) grouped together in clade 1 along with the f. spp. perniciosum, cubense, and canariensis with a bootstrap support of $86 \%$. When gaps were coded as a fifth character state, the same phylogeny was obtained with similar bootstrap support values (data not shown). Maximum likelihood analysis resulted in a tree nearly identical (slight differences in branch lengths) to that obtained in parsimony analysis with similar bootstrap values (Fig. 2).

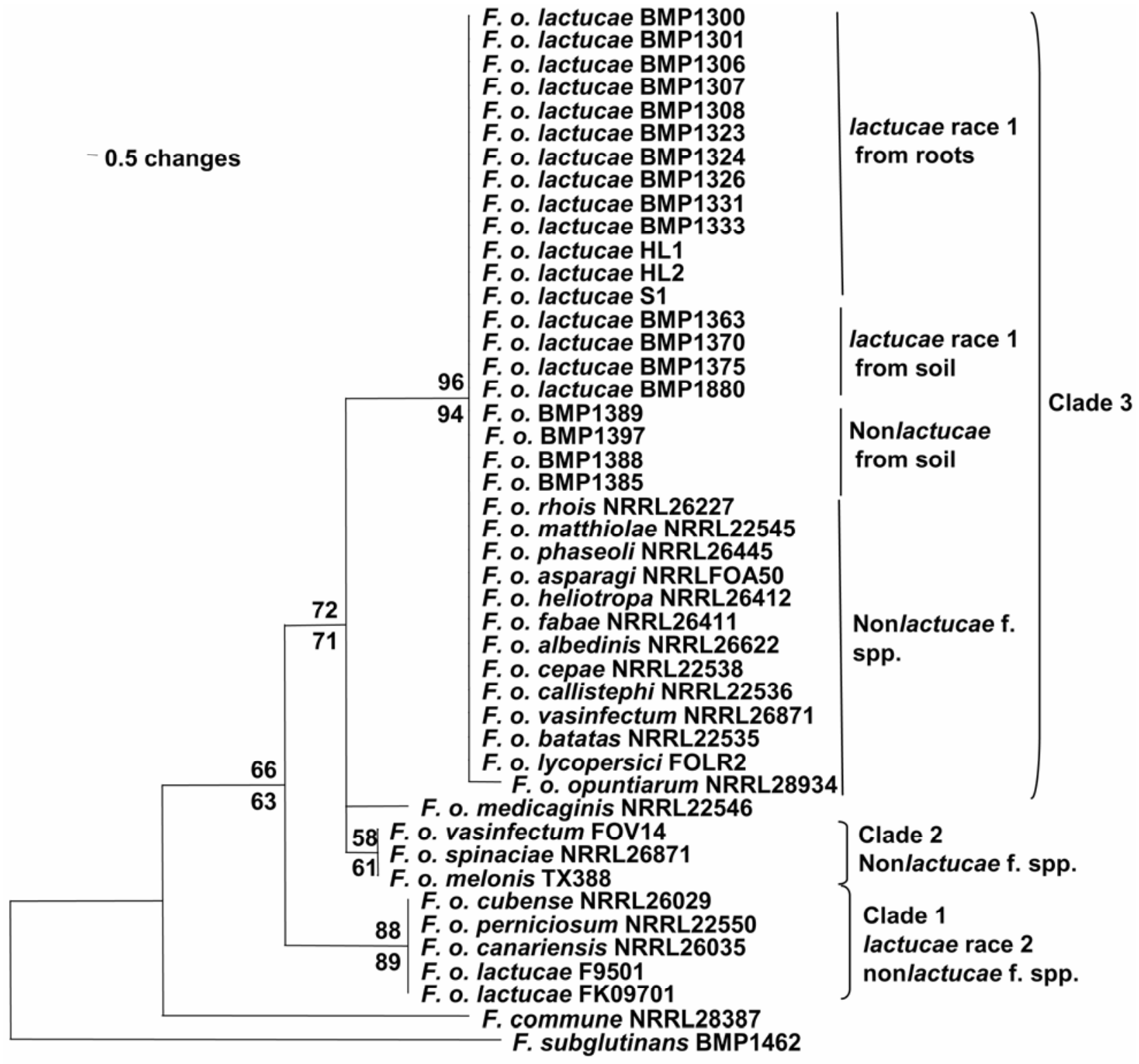

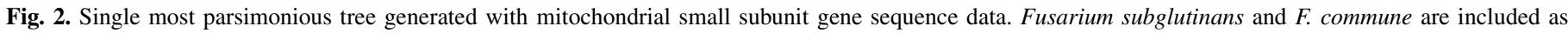

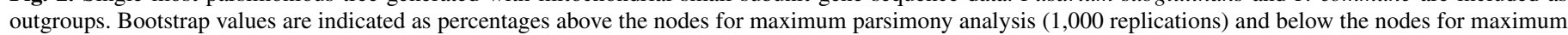

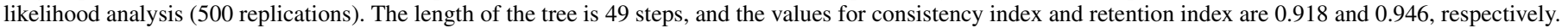


EF-1 $\alpha$ phylogeny. Alignment of the EF- $1 \alpha$ sequences generated a data set of 636 characters, of which $25(4.0 \%)$ characters were parsimony informative. Parsimony analysis yielded one MPT with four clades $($ steps $=63, \mathrm{CI}=0.968, \mathrm{RI}=0.978)($ Fig. 3). The lactucae race 1 isolates grouped together with seven other formae speciales (rhois, matthiolae, cepae, phaseoli, albedinis, heliotropa, and fabae), forming the major clade (clade 4) supported by a bootstrap value of $63 \%$. The nonpathogenic isolates from soil (BMP 1385, BMP1388, BMP1389, and BMP1397) formed a distinct clade (clade 3) with f. spp. asparagi, callistephi, batatas, vasinfectum 1 (NRRL25231), and lycopersici. The f. spp. opuntiarum and medicaginis were not included in either of the previous two clades, although $\mathrm{f}$. sp. oputiarum clustered with the two as part of the largest clade represented in the mtSSU tree. Clade 2 consisted of f. spp. spinaciae, vasinfectum 2, and melonis, with a bootstrap support value of $87 \%$. Isolates F9501 and FK09701, both belonging to race 2, again clustered with the f. spp. periciosum, cubense, and canariensis as clade 1, with bootstrap support of $96 \%$. Analysis with gaps treated as a fifth character state revealed the same phylogeny with similar bootstrap support values (data not shown). Maximum likelihood analysis resulted in a tree nearly identical to that obtained in parsimony analysis with similar bootstrap values (Fig. 3).
IGS phylogeny. Assembly of the IGS contigs and their alignment resulted in a data set of 2,226 characters, of which 195 $(8.8 \%)$ were parsimony informative. Parsimony analysis generated 40 MPT in which the lactucae race 1 isolates and f. spp. rhois, matthiolae, and phaseoli formed a monophyletic group as clade 6 (steps $=657, \mathrm{CI}=0.822, \mathrm{RI}=0.810$ ) (Fig. 4). Bootstrap support value for this group was $92 \%$. The f. spp. asparagi, callistephi, batatas, lycopersici, and vasinfectum 1 grouped together, with strong bootstrap support of $96 \%$ (clade 5). Clade 4 was made up of f. spp. albedinis, heliotropa, fabae, cepae, and medicaginis, with a bootstrap support of $52 \%$. Three of the nonpathogenic isolates (BMP1389, BMP 1397, and BMP 1388) from soil formed a distinct clade separated from the fourth nonpathogenic soil isolate, BMP1385 (clade 3). Clade 2 was composed of the f. spp. periciosum, cubense, and canariensis, with bootstrap support of $99 \%$. In contrast to groupings by $\mathrm{mtSSU}$ and EF- $1 \alpha$ sequences, clade 1 was made up solely of the lactucae isolates belonging to race 2 (F9501 and FK09701). The f. spp. opuntiarum, spinaciae, melonis, medicaginis, and vasinfectum 2 and soil isolate BMP1385 were resolved as individual lineages. The main differences between the 40 MPT trees were in the positions of the lactucae race 1 isolates from soil that oscillated between the subclade with lactucae race 1 isolates from roots and its present position on the tree. In addi-

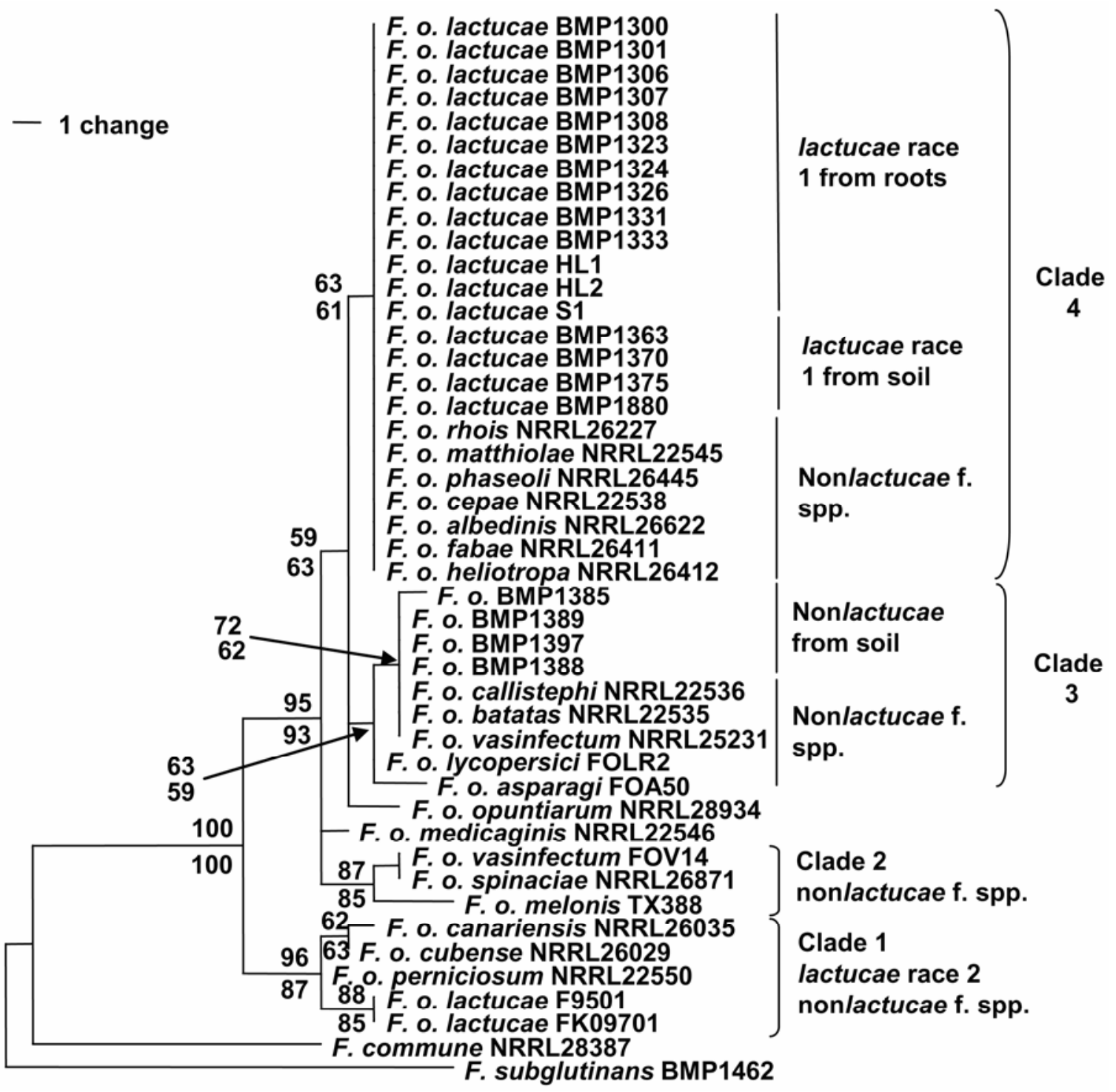

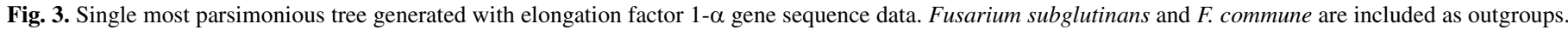

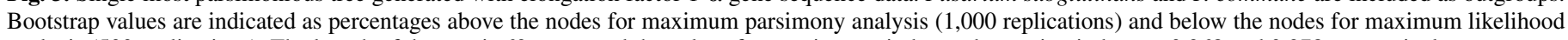
analysis (500 replications). The length of the tree is 63 steps, and the values for consistency index and retention index are 0.968 and 0.978 , respectively. 
tion, f. sp. medicaginis oscillated between clade 3 and forming an independent lineage. When gaps were coded as a fifth character state, the same phylogeny was obtained with similar bootstrap support values (data not shown). Maximum likelihood analysis resulted in a tree nearly identical to that presented in Figure 4 obtained in parsimony analysis (slight differences in relationships within clades 6 and 2) with similar bootsrap values (Fig. 4).

Analysis of the complete IGS sequence revealed numerous polymorphisms among the isolates. All lactucae race 1 isolates from tissue had identical IGS sequences. Three pathogenic race 1 isolates recovered from soil differed from pathogenic race 1 isolates recovered from lettuce roots by single nucleotide polymorphisms at three positions. Sequence comparison of the nonpathogenic $F$. oxysporum obtained from soil to sequences of lactucae race 1 isolates (both soil and root) revealed the presence of an 11-bp deletion in the nonpathogen sequences, as well as six insertions, nine transitions and, three transversions. The f. spp. medicaginis, fabae, heliotropa, and cepae shared a common 20-bp deletion at the same nucleotide position. The longest deletion in the IGS sequence was observed within f. sp. albedinis (22 bp). The lactucae race 2 isolates differed from race 1 isolates by the presence of three deletions, 11, 4, and $3 \mathrm{bp}$ in length, as well as several insertions at various nucleotide positions.
Analysis done specifically with the lactucae race 1 IGS sequence revealed the presence of several perfect and imperfect tandem repeats ranging in size between 12 and $36 \mathrm{bp}$. The consensus sequence GGTGTAGGGTAG was found within most of these repeats. Analysis of the repeat pattern of the IGS sequence without allowing for mismatch of base pairs yielded six repeats, with the longest being $22 \mathrm{bp}$. These repeat subunits were scattered over more than two-thirds of the IGS region, with the last 700 bases toward the $3^{\prime}$ end having no perfect repeats (Fig. 1B). Allowing for only one mismatch, the repeats extended to the $3^{\prime}$ end of the IGS and their number increased from 6 to 14 (data not shown).

Combined data analysis. The mtSSU, EF-1 $\alpha$, and IGS sequences were combined into a single matrix to conduct both the Mickevich-Farris and Partition-Homogeneity tests for data congruence and combinability for improvement of resolution of the taxa. The Mickevich-Farris test produced an index of 0.000 for the mtSSU and EF- $1 \alpha$ sequences, indicating total congruency between the two data sets (Table 4). Parsimony analysis of the combined $\mathrm{mtSSU}$ and EF-1 $\alpha$ yielded one most parsimonious trees of 112 steps $(\mathrm{CI}=0.946, \mathrm{RI}=0.964)$ with a topology nearly identical to that obtained with the EF-1 $\alpha$ data partition (data not shown). The same topology was obtained

\section{-5 changes}

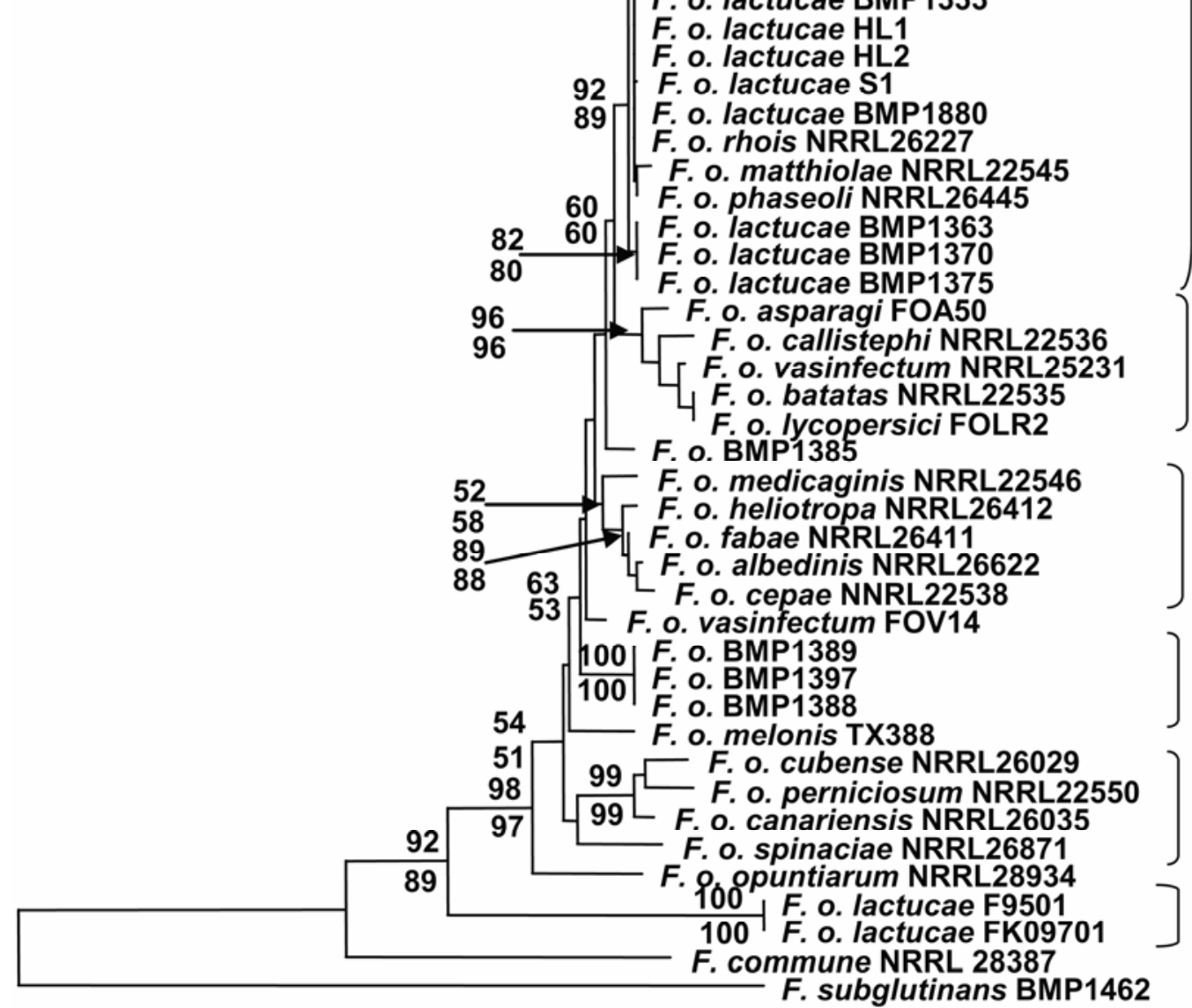

Clade 6 lactucae race 1 from roots, soil plus nonlactucae f. spp.

Clade 5 Nonlactucae f. spp.

Clade 4 Nonlactucae f. spp.

Clade 3 nonlactucae from soil

Clade 2 Nonlactucae f. spp.

Clade 1 lactucae race 2

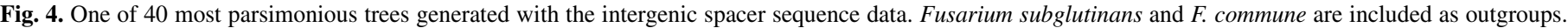

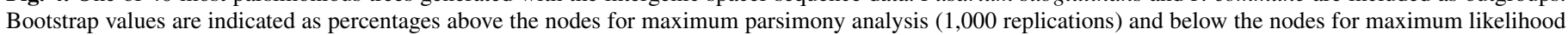
analysis (500 replications). The tree length is 657 steps, and the consistency index and retention index are 0.822 and 0.810 , respectively. 
when gaps were set either as missing data or as a fifth state (data not shown).

The Mickevich-Farris test produced an index of 0.078 for the mtSSU and IGS data sets, which can be interpreted as $7.8 \%$ incongruence between data partitions (Table 4). The corresponding $P$ value obtained with the $\mathrm{P}-\mathrm{H}$ test for these partitions was 0.0500 , suggesting incongruence if the threshold for incongruence is set at $P \leq 0.05$. Parsimony analysis of the combined mtSSU and IGS yielded 120 most parsimonious trees of 705 steps $(C I=0.818$, $\mathrm{RI}=0.807$ ), with a topology nearly identical to that obtained with the IGS data set (data not shown). The primary differences observed in topologies from the combined data set compared with the IGS data set were the clustering of f. sp. opuntiarum with the nonpathogenic isolates from soil and the formation of an independent lineage by f. sp. medicaginis. Slight differences in topologies were observed when gaps were set either as missing data or as a fifth state (data not shown). On the tree generated with gaps treated as missing data, the f. sp. vasinfectum 2 and melonis clustered together and f. spp. spinaciae and medicaginis constituted independent lineages. When gaps were treated as a fifth state, the f. spp. melonis and spinaciae clustered together and f. sp. vasinfectum 2 clustered with non-lactucae isolates of clade 3 of the IGS phylogram. In addition, f. sp. medicaginis grouped with isolates of clade 4 and f. sp. opuntiarum formed an independent lineage. Maximum likelihood analysis resulted in a tree nearly identical (slight differences in relationships within clades 4,3 , and 2) to that obtained in parsimony analysis with similar bootstrap values (data not shown).

The $I_{\mathrm{MF}}$ for the combined EF- $1 \alpha$ and IGS data sets and the combined mtSSU, EF- $1 \alpha$, and IGS data sets were 0.121 and 0.155 , respectively, revealing considerably more character incongruence than that found between the mtSSU and IGS data sets (Table 4). P-H test values for both of these sets were 0.0100, supporting the findings of the $I_{\mathrm{MF}}$. Parsimony analysis of the three combined data sets yielded 800 MPT with topologies very similar to that of the IGS data set (steps $=792, \mathrm{CI}=0.816, \mathrm{RI}=0.813$ ) (Fig. 5). The primary differences observed in topologies from the combined data set compared with the IGS data set were the inclusion of isolate BMP1385 within clade 4 , the movement of clade 4 relative to clade 5 of the IGS tree, and the clustering of $\mathrm{f}$. sp. spinaciae with the $\mathrm{f}$. spp. melonis and vasinfectum 2 . The $\mathrm{f}$. $\mathrm{sp}$. medicaginis still formed an independent lineage in most trees. Similar topologies were obtained when gaps were set either as missing data or as a fifth state (data not shown). Maximum likelihood analysis resulted in a tree nearly identical to the most parsimonious tree presented in Figure 5 (slight differences in branch lengths) with similar bootstrap values (Fig. 5).

Test of hypothesis. Three hypotheses of groupings were tested with the parsimony criterion (Fig. 6). The first hypothesis (A) was drawn from the grouping based on the mtSSU sequence data (Fig. 6A). In this hypothesis, there are four lineages of $F$. oxysporum, with the lactucae race 2 isolates forming the first lineage and the

TABLE 4. Congruency of data partitions as evaluated by Mickevich-Farris incongruence metrics $\left(I_{\mathrm{MF}}\right)$ and the Partition-Homogeneity $(\mathrm{P}-\mathrm{H})$ test implemented in PAUP'

\begin{tabular}{|c|c|c|c|c|}
\hline \multirow[b]{2}{*}{ Data set ${ }^{\mathrm{y}}$} & \multicolumn{2}{|c|}{ Steps } & \multirow[b]{2}{*}{$I_{\mathrm{MF}}$} & \multirow[b]{2}{*}{ P-H test $(P)^{2}$} \\
\hline & Parsimony & Minimum & & \\
\hline $\mathrm{mtSSU} / \mathrm{EF}-1 \alpha$ & 112 & 106 & 0.000 & 1.0000 \\
\hline mtSSU/IGS & 705 & 577 & 0.078 & $0.0500 *$ \\
\hline EF-1 $1 \alpha /$ IGS & 725 & 593 & 0.121 & $0.0100 *$ \\
\hline $\mathrm{mtSSU} / \mathrm{EF}-1 \alpha / \mathrm{IGS}$ & 780 & 638 & 0.155 & $0.0100 *$ \\
\hline
\end{tabular}

x Tree lengths (steps) used to determine the $I_{\mathrm{MF}}$ are indicated for maximum parsimony analysis and minimum number of synapomorphies.

${ }^{\mathrm{y}} \mathrm{mtSSU}=$ mitochondrial small subunit, $\mathrm{EF}-1 \alpha=$ elongation factor $1-\alpha$, and IGS = intergenic spacer.

${ }^{\mathrm{z}}$ Asterisk (*) indicates $P \leq 0.05$ is considered to be significantly incongruent. lactucae race 1 and 17 other formae speciales forming the fourth lineage. The second hypothesis was drawn from groupings based on the EF- $1 \alpha$ data set (Fig. 6B). In this hypothesis, there are six lineages of $F$. oxysporum, four of which correspond to the fourth lineage in hypothesis A. The third hypothesis (C) was drawn from groupings based upon the IGS data (Fig. 6C). In this hypothesis, there was further resolution of most of the lineages in hypothesis B. In particular, the melonis-vasinfectum 2-spinaciae group, which formed a monophyletic lineage in hypotheses A and B, was resolved into three different lineages in hypothesis $\mathrm{C}$.

Heuristic search with the mtSSU data under the constraint of Figure $6 \mathrm{~B}$ and $\mathrm{C}$ produced one equally parsimonious tree of 49 steps and two equally parsimonious trees of 61 steps, respectively. The null hypothesis of no difference between the best trees and trees reconstructed under the constraint of Figure $6 \mathrm{~B}$ was not rejected by the $\mathrm{KH}$, Templeton, and WS tests, implying that hypotheses B is consistent with the mtSSU data (Table 5). However, the null hypothesis was rejected under the constraint of Figure $6 \mathrm{C}$, implying that hypothesis $\mathrm{C}$ is inconsistent with the mtSSU data.

Heuristic search with the EF-1 $\alpha$ data under the constraints of Figure 6A and $\mathrm{C}$ produced one parsimonious tree of 64 steps $(\mathrm{CI}=0.953, \mathrm{RI}=0.967)$ and two equally parsimonious trees of 80 steps $(\mathrm{CI}=0.762, \mathrm{RI}=0.791)$, respectively. The null hypothesis of no difference between the best tree and trees reconstructed under the constraint of Figure 6A was not rejected, implying that hypothesis A was consistent with the EF-1 $\alpha$ data (Table 5). However, the null hypothesis was rejected under the constraint of Figure 6C, implying that hypothesis $\mathrm{C}$ is inconsistent with the EF$1 \alpha$ data.

Heuristic search with the IGS data under the constraints of Figure $6 \mathrm{~A}$ and $\mathrm{B}$ produced 100 equally parsimonious trees of 689 steps $(\mathrm{CI}=0.772, \mathrm{RI}=0.743)$ and 6 equally parsimonious trees of 727 steps $(\mathrm{CI}=0.732$, $\mathrm{RI}=0.681)$, respectively. The null hypothesis of no difference between the best tree and trees constructed under the constraints of Figure $6 \mathrm{~B}$ and $6 \mathrm{C}$ was rejected by $\mathrm{KH}$, Templeton, and WS tests (Table 5), which implies that both hypothesis A and B are inconsistent with the IGS data.

\section{DISCUSSION}

The primary focus of this study was to examine phylogenetic relationships among f. sp. lactucae isolates and between lactucae, other formae speciales, and nonpathogenic isolates of $F$. oxyspor$u m$, which resulted in several significant conclusions. First, this study revealed that $F$. oxysporum f. sp. lactucae is composed of at least two independent clonal lineages. All race 1 isolates from Arizona, California, and Japan had identical mtSSU and EF- $1 \alpha$ sequences, and nearly identical IGS sequences, which suggests a common origin. Similarly, both race 2 isolates had identical $\mathrm{mtSSU}, \mathrm{EF}-1 \alpha$, and IGS sequences. However, all loci showed very significant sequence divergence between race 1 and 2 , and phylogenetic analyses revealed that the races were only distantly related. These findings were similar to those obtained by Fujinaga et al. (11) using only partial IGS sequences. Fujinaga et al. also examined race 3 , which was not available for this study, and found that it was genetically distinct from both race 1 and 2, suggesting yet another lineage of $F$. oxysporum f. sp. lactucae. In addition, Ogiso et al. (29) found a strong correlation between race and vegetative compatibility in $F$. oxysporum $\mathrm{f}$. sp. lactucae, and revealed that California race 1 isolates were of the same vegetative compatibility group (VCG) as race 1 from Japan and that all race 2 isolates were of a separate VCG. Similarly, Pasquali et al. (30) found that race 1 isolates from Italy, Arizona, and California and type 1 isolates from Taiwan were all of the same VCG as the race 1 isolates from Japan, which was different from that of race 2 from Japan. These studies further demonstrate that pathogenicity of $F$. oxysporum to lettuce evolved in two independent 
lineages, given the apparent polyphyly. What is most interesting is the fact that all three f. sp. lactucae races first were detected and currently are found together only in Japan, revealing considerable diversity in $F$. oxysporum strains from this geographic region. Indeed, O'Donnell (27) reported similar genetic diversity among F. oxysporum formae speciales of Asian host genera Musa, Albizia, and Phoenix and suggested that Asia may be the center of origin of the $F$. oxysporum complex.

A second finding was that, of the three loci analyzed (mtSSU, EF- $1 \alpha$, and IGS), the IGS region contained the most sequence variation and provided the best resolution of the lactucae isolates as distinct taxa. Based upon the IGS sequences, f. sp. rhois was genetically identical to isolates of $\mathrm{f}$. sp. lactucae recovered from lettuce tissue (pathogenicity tests conducted on the three lettuce cultivars with f. sp. rhois were negative). The next most closely related taxa were the f. spp. matthiolae and phaseoli, which also grouped with race 1 isolates. These relationships were consistent among the three data sets. Although the EF-1 $\alpha$ gene has been used in most studies for phylogenetic resolution within and between some formae speciales of $F$. oxysporum, it did not contain enough variation to separate the f. sp. lactucae race 1 isolates from seven other formae speciales. In previous studies using EF$1 \alpha$ and $\mathrm{mtSSU}$ sequences, $F$. oxysporum was shown to comprise three major clades, within which could be found a combination of formae speciales forming distinct lineages $(5,27)$. The trees generated from the mtSSU data set in this study also revealed three primary clades. The EF- $1 \alpha$ data generated four clades, two of which were equivalent to clade 3 in the mtSSU analysis. However, the IGS data set generated six clades, with many formae speciales unclustered as separate lineages. In addition, analysis of the IGS region even revealed differences among f. sp. lactucae race 1 isolates, with three of the isolates recovered from soil clustering separately. For both mtSSU and EF-1 $\alpha$ alignments, race 2 isolates clustered with three other formae speciales in a single clade that was basal to the other formae speciales examined. However, analysis of the IGS data resolved the lactucae race 2 isolates as a monophyletic group basal to all other formae speciales examined. Additional taxa that may group within the race 2 clade can be ascertained only through a more comprehensive review of all formae speciales within F. oxysporum. Con-
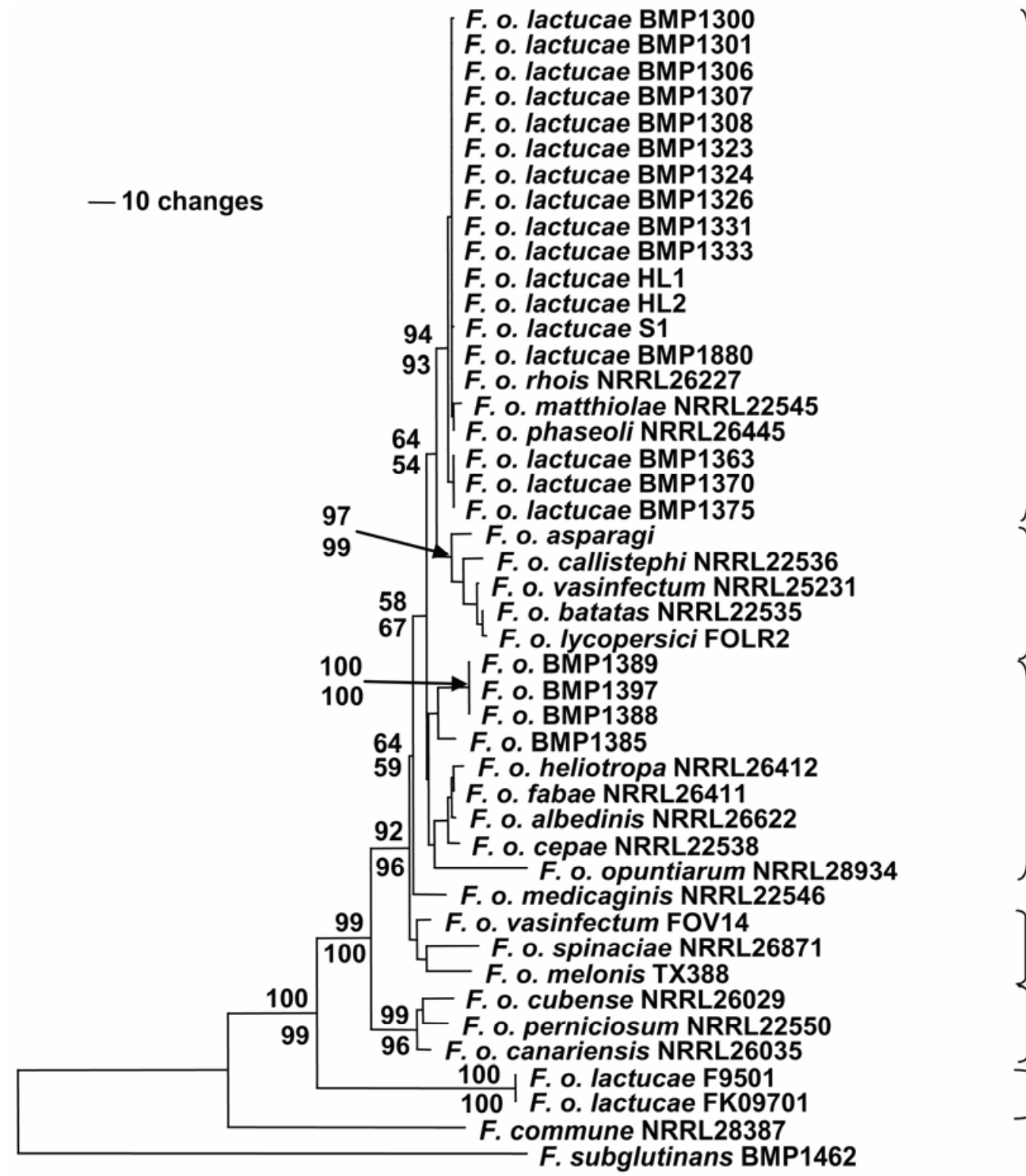

\section{Clade 6 \\ lactucae race 1 \\ From roots, \\ soil, plus \\ nonlactucae f. spp.}

Clade 5

Nonlactucae f. spp.

\section{Clade 4 \\ Nonlactucae f. spp.}

\section{Clade 3}

Nonlactucae f. spp.

Clade 2

Nonlactucae f. spp.

Clade 1

lactucae race 2

Fig. 5. One of 800 most parsimonious trees generated with combined mitochondrial small subunit, elongation factor 1- $\alpha$, and intergenic spacer sequence data. Fusarium subglutinans and $F$. commune are included as outgroups. Bootstrap values are indicated as percentages above the nodes for maximum parsimony analysis (1,000 replications) and below the nodes for maximum likelihood analysis (500 replications). The tree length is 792 steps, and the consistency index and retention index are 0.816 and 0.813 , respectively. 
sidering there are over 120 reported formae speciales (4), it is highly likely that future analyses will reveal taxa that are closely related to and cluster with the race 2 isolates of $\mathrm{f}$. sp. lactucae.

The IGS and the mtSSU and EF- $1 \alpha$ trees presented conflicting topologies, as was demonstrated by differences in the relative positions of the taxa medicaginis, opuntiarum, and spinaciae and the nonpathogens from soil. This conflict was revealed in various tests used to determine the combinability of the data sets as well as examine conflicts between their topologies. The results of the
Mickevich-Farris $\left(I_{\mathrm{MF}}\right)$ and P-H tests suggested that the IGS and the mtSSU and EF-1 $\alpha$ data sets were incongruent. Tests of topological hypotheses supported this conclusion. Whereas hypothesis A, based upon mtSSU sequence data, was consistent with the EF$1 \alpha$ data sets, it was inconsistent with the IGS data set. Hypothesis $\mathrm{B}$, based upon EF-1 $\alpha$ sequence data, was consistent with the mtSSU data but inconsistent with IGS data. Likewise, hypothesis $\mathrm{C}$, based on IGS sequence data, was inconsistent with both the $\mathrm{mtSSU}$ and EF-1 $\alpha$ data. The incongruence between these three
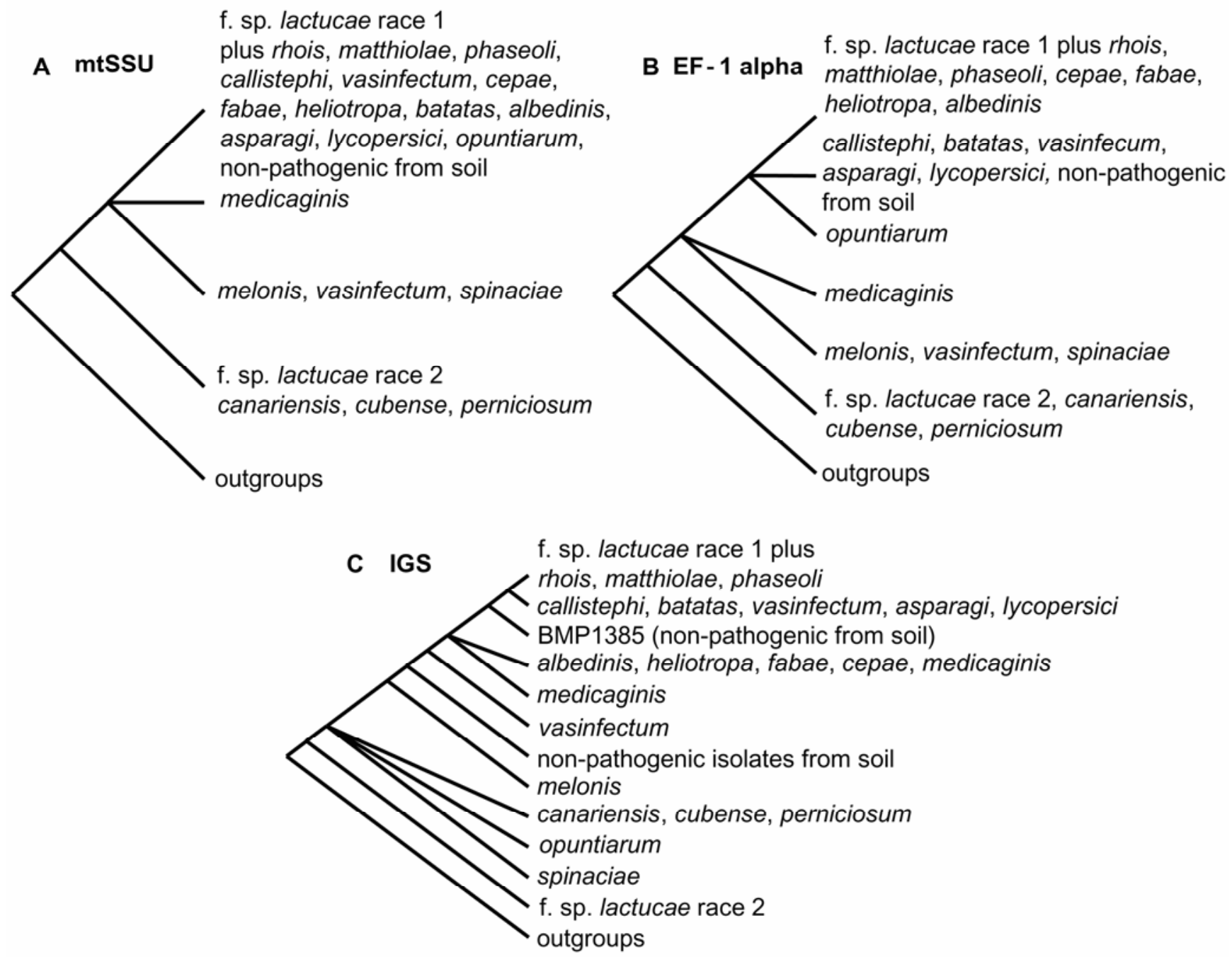

Fig. 6. Three strict consensus trees generated in PAUP from the different data sets used in the hypothesis tests. A, Mitochondrial small subunit (mtSSU) data set; $\mathbf{B}$, elongation factor $1-\alpha(E F-1 \alpha)$ data set; and $\mathbf{C}$, intergenic spacer (IGS) data set.

TABLE 5. Test of topological hypotheses under varying constraints of strict consensus trees

\begin{tabular}{|c|c|c|c|c|c|}
\hline \multirow[b]{2}{*}{ Data set ${ }^{w}$} & \multirow[b]{2}{*}{ Constraints $^{\mathrm{x}}$} & \multirow[b]{2}{*}{ Steps ${ }^{\mathrm{y}}$} & \multicolumn{3}{|c|}{$P$ values ${ }^{\mathrm{z}}$} \\
\hline & & & $\mathrm{KH}$ & TT & WS \\
\hline mtSSU & EF-1 $\alpha$ & $49(49)$ & 1.0000 & $\ldots$ & \\
\hline $\mathrm{EF}-1 \alpha$ & IGS & $80(63)$ & $0.0022 *$ & $0.0027 *$ & $0.0010 *$ \\
\hline \multirow[t]{2}{*}{ IGS } & $\mathrm{mtSSU}$ & 689 (646) & $<0.0001^{*}$ & $<0.0001 *$ & $<0.0001^{*}$ \\
\hline & $\mathrm{EF}-1 \alpha$ & $738(646)$ & $<0.0001 *$ & $<0.0001 *$ & $<0.0001^{*}$ \\
\hline
\end{tabular}

${ }^{\mathrm{w}}$ Values in parentheses represent steps of the unconstrained best tree.

${ }^{x}$ Values shown for Kishino-Hasegawa (KH), Templeton (TT), and Winning-sites (WS) tests. The rank sums for both the WS and TT tests were 0.00 for mitochondrial small subunit (mtSSU) data set under hypothesis B constraint; thus, $P$ values were not generated; $*$ indicates that $P \leq 0.05$ is considered to be significantly incongruent.

${ }^{y}$ EF- $1 \alpha=$ elongation factor $1-\alpha$ and IGS $=$ intergenic spacer.

${ }^{z}$ The parsimony criterion also was used to test congruency of data sets against hypotheses for groupings drawn from results from mtSSU, EF-1 $\alpha$, and IGS sequence data. For each data set, a strict consensus tree was generated and used as a topological hypothesis. 
data sets suggests that combining them may result in misrepresentation of phylogenetic relationships. Proponents of conditional combination recommend analyzing incongruent data partitions individually until more information is available on the nature of incongruency (7). However, the question as to what constitutes incongruency and when to combine data partitions for phylogenetic analysis remains controversial. Farias et al. (8) considered a significance of $P \leq 0.05$ for the $\mathrm{P}-\mathrm{H}$ test, which is a frequently used threshold to determine data incongruency, to be too conservative and suggested that a significance of $P \leq 0.01$ is a more appropriate threshold. Cunningham (7) further demonstrated that, at heterogeneity values of $P>0.01$, combining data still could improve phylogenetic accuracy, whereas combining data at $P<$ 0.001 could lead to wrong phylogenetic interpretations. However, for the data sets used in this study, tests of hypotheses supported maintaining a P-H test threshold of $P \leq 0.05$ as a measure of incongruence. When the three data partitions were combined $(P=$ 0.01 ) and analyzed, clade 2 (f. spp. melonis, vasinfectum FOV14, and spinaciae), which was present on the mtSSU and EF-1 $\alpha$ trees but not on the IGS tree, was recovered. However, other significant conflicts remained. Resolution of such conflicts may be found in recent studies on topology tests which revealed that single or few genes could have significant probabilities of supporting conflicting topologies, particularly if there is insufficient representation among taxa (32). Because this study included only 40 taxa, including 20 different formae speciales of $F$. oxysporum, there is a possibility of under representation. Indeed, O'Donnell et al. examined a larger number of $F$. oxysporum isolates $(n=131)$ obtained from more diverse host and geographic sources, and subsequent topology tests revealed that EF-1 $\alpha$ and IGS data were not significantly incongruent (28). This suggests that the inclusion of additional and more diverse isolates may resolve some of the conflict revealed in this study. The inclusion of more taxa also may improve low bootstrap support evident on several of the intermediate nodes.

Regardless of taxon representation, discordance between rDNA genealogies and those of protein-coding genes has been documented previously. In studies on phylogenetic relationships within the Gibberella fujikuroi complex of Fusarium and related species, it was discovered that all taxa examined $(n=23)$ contained two nonorthologous nuclear rDNA internal transcribed spacer (ITS)2 types whose genealogies were different from those of the mtSSU rDNA, nuclear 28S rDNA, and $\beta$-tubulin gene (26). It was hypothesized that the divergence between ITS2 types was due to an ancient interspecific hybridization event or gene duplication that occurred prior to the evolutionary radiation of the fungal lineages. A nonuniform distribution of the ITS2 types among subsequent species lineages resulted in a homoplastic pattern of evolution which obscured true phylogenetic relationships. Similarly, different IGS sequence types have been reported in an isolate of F. oxysporum f. sp. melonis, as well as in two putatively nonpathogenic forms of the fungus (3). Therefore, similar systematic problems may be expected with the use of IGS sequences in phylogenetic analyses. Other factors, such as unequal rates of evolution between loci and incomplete concerted evolution within loci, also have been proposed to explain discrepancies between rDNA and other data sets (34). These factors also may have relevance in the apparent discordance between IGS-based genealogy of $F$. oxysporum formae speciales and those based upon mtSSU and EF- $1 \alpha$ data that was revealed in this study.

The IGS sequence of $F$. oxysporum f. sp. lactucae contains several repeated subunits, most of which contained a common consensus sequence of $12 \mathrm{bp}$ and several imperfect permutations of this same repeat. Analysis of the repeats was done without allowing for any mismatch of base pairs and only six repeated sequences were obtained. However, when one mismatch and two mismatches of base pairs were allowed, the number of repeats increased to 21 and 28, respectively. Similar analysis of IGS sequences of three Verticillium spp. also revealed several repeats located between nucleotides 203 to $1,264 \mathrm{bp}$ from the $5^{\prime}$ end. In that study, one $V$. longisporum contained 14 perfect 39-bp repetitive motifs; whereas, in other isolates of $V$. longisporum, $V$. dahliae, and V. albo-atrum, the corresponding regions were made up of imperfect permutations of the 39-bp motif. The rest of the IGS contained no repeated sequences (31). In contrast, the perfect repeats found in $\mathrm{f}$. sp. lactucae were distributed along more than two-thirds of the IGS, with only the far $3^{\prime}$ end being free of repeat units. This portion of the IGS was relatively conserved among the F. oxysporum isolates examined in this study, and it has been hypothesized that conserved IGS regions may accommodate functions related to rDNA production or processing (31). Additional studies are needed to determine whether the use of this region in the absence of the much larger portion of the IGS that contains repeat units improves phylogenetic utility of IGS data and results in less conflict with other genetic loci.

In summary, potential conflicts between IGS data and those from other genetic loci may make portions of the IGS deficient for robust resolution of $F$. oxysporum formae speciales phylogeny. However, considerable sequence variation among closely related taxa suggests that it can be used effectively as a diagnostic marker to differentiate among pathogenic and nonpathogenic isolates of F. oxysporum, including the f. sp. lactucae. Based on the heterogeneity of the IGS region, sensitive and specific PCR primers currently are being developed for the diagnosis of $F$. oxysporum $\mathrm{f}$. sp. lactucae in field soil, lettuce seed, and in planta as an additional tool for the management of Fusarium wilt of lettuce in Arizona and California.

\section{ACKNOWLEDGMENTS}

This work was supported in part by the Arizona Iceberg Lettuce Research Council and the College of Agriculture and Life Sciences, University of Arizona. We thank K. O'Donnell for providing the NRRL isolates and several of the IGS sequences used in this study, and T. Gordon and E. Nigh for providing additional isolates.

\section{LITERATURE CITED}

1. Anderson, J. B., and Stasovski, E. 1992. Molecular phylogeny of Northern Hemisphere species of Armillaria. Mycologia 84:505-516.

2. Appel, D. J., and Gordon, T. R. 1995. Intraspecific variation within populations of Fusarium oxysporum based on RFLP analysis of the intergenic spacer (IGS) region of the rDNA. Exp. Mycol. 19:120-128.

3. Appel, D. J., and Gordon, T. R. 1996. Relationships among pathogenic and nonpathogenic isolates of Fusarium oxysporum based on the partial sequences of the intergenic spacer region of the ribosomal DNA. Mol. Plant-Microbe Interact. 9:125-138.

4. Armstrong, G. M., and Armstrong, J. K. 1981. Formae speciales and races of Fusarium oxysporum causing wilt diseases. Pages 391-399 in: Fusarium: Diseases, Biology, and Taxonomy. P. E. Nelson, T. A. Tousson, and R. J. Cook, eds. The Pennsylvania State University Press, University Park.

5. Baayen, R. P., O’Donnell, K., Bonants, J. M., Cigelnik, E., Kroon, L. P. N., Roebroeck, M E. J. A., and Waalwijk, C. 2000. Gene genealogies and AFLP analyses in the Fusarium oxysporum complex identify monophyletic and nonmonophyletic formae speciales causing wilt and rot disease. Phytopathology 90:891-900.

6. Burgess, W. L., Summerell, B. A., Bullock, S., Gott, K. P., and Backhouse, D. 1994. Laboratory Manual for Fusarium Research, 3rd ed. University of Sydney and Royal Botanic Gardens, Sydney, Australia.

7. Cunningham, C. W. 1997. Can three incongruence test predict when data should be combined? Mol. Biol. Evol. 14(7):733-740.

8. Farias, I. P., Orti, G., and Meyer, A. 2000. Total evidence: Molecules, morphology, and the phylogeny of Cichlid fishes. J. Exp. Zool. 288:7692

9. Fitch, W. M. 1971. Towards defining the course of evolution: Minimum change for a specific tree topology. Syst. Zool. 20(4):406-416.

10. Fujinaga, M., Hiseki, O., Nobuski, T., Hideki, D., Shigeru, Y., and Masayuki, N. 2003. Race 3, a new species of Fusarium oxysporum f. sp. lactucae determined by a differential system with commercial cultivars. J. Gen. Plant Pathol. 69:23-28. 
11. Fujinaga, M., Ogiso, H., Shinohara, H., Tsushima, S., Nishimura N., Togowa, M., Saito, H., and Nosue, M. 2005. Phylogenetic relationships between the lettuce root rot pathogen Fusarium oxysporum f. sp. lactucae race 1,2 , and 3 based on the sequence of the intergenic spacer region of its ribosomal DNA. J. Gen. Plant Pathol. 71:402-407.

12. Garibaldi, A., Gilardi, G., and Guilino, M. L. 2002. First report of Fusarium oxysporum on lettuce in Europe. Plant Dis. 86:1052.

13. Goldman, N., Anderson, J. P., and Rodrigo, A. G. 2000. Likelihood-based tests of topologies in phylogenetics. Syst. Biol. 49(4):652-670.

14. Gordon, T. R., and Martyn, R. D. 1997. The evolutionary biology of Fusarium oxysporum. Annu. Rev. Phytopathol. 35:111-128.

15. Hasegawa, M., and Kishino, H. 1989. Confidence limits on the maximum-likelihood estimate of the hominoid tree from mitochondrialDNA sequences. Evolution 43:672-677.

16. Hofstetter, V., Clémençon, H., Vilgalys, R., and Moncalvo, J-M. 2002. Phylogenetic analyses of the Lyophylleae (Agaricale, Basidiomycota) based on nuclear and mitochondrial rDNA sequences. Mycol. Res. 106(9):1043-1059.

17. Huang, J. H., and Lo, C. T. 1998. Wilt of lettuce caused by Fusarium oxysporum in Taiwan. Plant Pathol. Bull. 7:150-153.

18. Hubbard, J. C., and Gerik, J. S. 1993. A new wilt disease of lettuce incited by Fusarium oxysporum f. sp. lactucum forma specialis nov. Plant Dis. 77:7.

19. Komada, H. 1975. Development of a selective medium for quantitative isolation of Fusarium oxysporum from natural soils. Rev. Plant Prot. Res. 8:114-125.

20. Li, K. N., Rouse, D. I., and German, T. L. 1994. Differentiation of ascomycetes with PCR primers. Appl. Environ. Microbiol. 60:4324-4331

21. Matheron, M. E., and Koike, S. T. 2003. First report of Fusarium wilt of lettuce caused by Fusarium oxysporum f. sp. lactucae in Arizona. Plant Dis. 87:1265.

22. Matuo, T., and Motohashi, S. 1967. On Fusarium oxysporum f. sp. lactucae n. f. causing root rot of lettuce. Trans. Mycol. Soc. Jpn. 32:1315 .

23. McCreight, J. D., Matheron, M. E., Tickes, B. R., and Platts, B. 2005. Fusarium wilt race 1 on lettuce. HortScience 40(3):529-531.

24. Mickevich, M. F., and J. S. Farris. 1981. The implication of congruence in Menidia. Syst. Zool. 30:351-370.

25. Millani, M. J., Etebarian, H. R., and Alizadeh, A. 1999. Occurrence of Fusarium wilt of lettuce in Shahre-Ray, Varamin and Karaj areas. Iran. J.
Plant Pathol. 35:44-45.

26. O’Donnell, K., and Cigelnik, E. 1997. Two divergent intragenomic rDNA ITS2 types within a monophyletic lineage of the fungus Fusarium are nonorthologous. Mol. Phylogenet. Evol. 7(1):103-116.

27. O’Donnell, K., Kistler, H. C., Cigelnik, E., and Ploetz, R. C. 1998. Multiple evolutionary origin of the fungus causing Panama disease of banana; concordant evidence from nuclear and mitochondrial gene genealogies. Pro. Natl. Acad. Sci. USA 95:2044-2049.

28. O’Donnell, K., Sutton, D. A., Rinaldi, M. G., Magnon, K. C., Cox, P. A., Revankar, S. G., Sanche, S., Geiser, D. M., Juba, J. H., Van Burik, J. A., Padhye, A., Anaissie, E. J., Francesconi, A., Walsh, T. J., and Robinson, J. S. 2004. Genetic diversity of human pathogenic members of the Fusarium oxysporum complex inferred from multilocus DNA sequence data and amplified fragment length polymorphism analyses: evidence for the recent dispersion of a geographically widespread clonal lineage and nosocomial origin. J. Clin. Microbiol. 42(11):5109-5120.

29. Ogiso, H., Fujinaga, M., Daito H., Takehara, T., and Yamanaka, S. 2002. Physiological races and vegetative compatibility groups of Fusarium oxysporum f. sp. lactucae isolated from crisphead lettuce in Japan. J. Gen. Plant Pathol. 68:292-299.

30. Pasquali, M., Dematheis, F., Gilardi G., Gullino, M. L., and Garibaldi A. 2005. Vegetative compatibility groups of Fusarium oxysporum f. sp. lactucae from lettuce. Plant Dis. 89(3):237-240.

31. Pramateftaki, P. V., Antoniou, P. P., and Typas, M. A. 2000. The complete DNA sequence of the nuclear ribosomal RNA gene complex of Verticillium dahliae: Intraspecific heterogeneity within the intergenic spacer region. Fungal Genet. Biol. 29:19-27.

32. Rokas, A., Williams, B. L., King, N., and Carroll, B. S. 2003. Genomescale approaches to resolving incongruency in molecular phylogenies. Nature 425:798-804.

33. Skovgaard, K., Nirenberg, H. I., O’Donnell, K., and Rosendahl, S. 2001. Evolution of Fusarium oxysporum f. sp. vasinfectum races inferred from multigene genealogies. Phytopathology 91:1231-1237.

34. Sullivan, J. 1996. Combining data with different distributions of amongsite variation. Syst. Biol. 45:375-380.

35. White, T. J., Bruns, T. Lee, S., and Taylor, J. 1990. Amplification and direct sequencing of fungal ribosomal RNA genes for phylogenetics. Pages 315-322 in: PCR Protocols: A Guide to Methods and Amplifications. M. A. Innis, D. H. Gelfand, J. J. Sninsky, and T. J. White, eds. Academic Press, Inc., San Diego, CA. 